\title{
OBITUARY
}

\section{Alan Seymour Philps}

FRIENDS and colleagues of Seymour Philps have watched with distress the deterioration of his health during the past two years.

He himself knew of the incurable nature of his malady but with undaunted courage he carried on his work until recently.

When I saw him a few weeks ago Seymour told me that being able to spend his days at home with his family free from the cares of professional duties he was happier than he had been for some years.

Born on February 28, 1906, the son of Mr. Francis John Philps, former editor of the Financial Times, he died on April 26, 1956.

From Aldenham School he entered St. Bartholomew's Hospital in 1924, qualifying in 1929. Following an appointment as house surgeon to Professor George Gask and Sir Thomas Dunhill, Philps obtained his F.R.C.S. in 1931.

He was for a few years on the medical staff of the London Transport Board, then his interest turned to ophthalmology, and various junior eye appointments followed: house surgeon to the Royal Westminster Ophthalmic Hospital in 1936, out-patient officer at Moorfields, and chief assistant in the Eye Dopartment of St. Bartholomew's 1937. In 1938, Philps was appointed assistant surgeon to the Royal Westminster Ophthalmic Hospital and full surgeon in 1944. He was also ophthalmic surgeon to the Victoria Hospital for Children and to the Miller General Hospital, Greenwich.

During the early years of the war he worked for the Emergency Medical Services in the St. Albans Sector. Joining the R.A.M.C. in 1942, he was appointed to the Colchester Military Hospital, and for a time was adviser in ophthalmology to the War Office. Later, Philps served abroad, taking part in the Normandy landing and the advance into Belgium. During the latter part of his service he was ophthalmic adviser at Millbank Hospital and attained the rank of Lt.-Col. After demobilization in October, 1946, he returned to his hospital and consultant duties.

In 1947 he was elected assistant ophthalmic surgeon to St. Bartholomew's Hospital and in 1948 was appointed surgeon-in-charge of the Eye Department. With the inception of the National Health Service in 1948, he became consultant ophthalmic surgeon to the Mid-Herts group of hospitals and secretary of the Ophthalmic Advisory Committee of N.E. Metropolitan Regional Hospital Board. In 1951 he was appointed by the London University to be a teacher of ophthalmology at the Institute of Ophthalmology and at St. Bartholomew's Hospital Medical School.

Gifted with great manual dexterity, Seymour Philps was a brilliant surgeon. Interested an all branches of his specialty, he was a wise and most sympathetic clinician with a flair for teaching. Latterly he had a large private practice, but his hospital and the welfare of the patients he saw there always came first.

Widely read, he had a large collection of ophthalmic literature which it is hoped may form the nucleus of an ophthalmological library abroad. In addition to contributing to medical journals and the Encyclopaedia of Medical Practice, Philps was the author of Ophthalmic Operations (1950). This work was profusely illustrated with his own exquisite drawings and photographs.

In 1953, shortly before the onset of his illness, he was invited to visit Australia by the Ophthalmological Society of the Dominion, where he addressed numerous meetings. He returned by way of America and Canada. He also visited many eye clinics in Europe, thus widening his already extensive knowledge. 


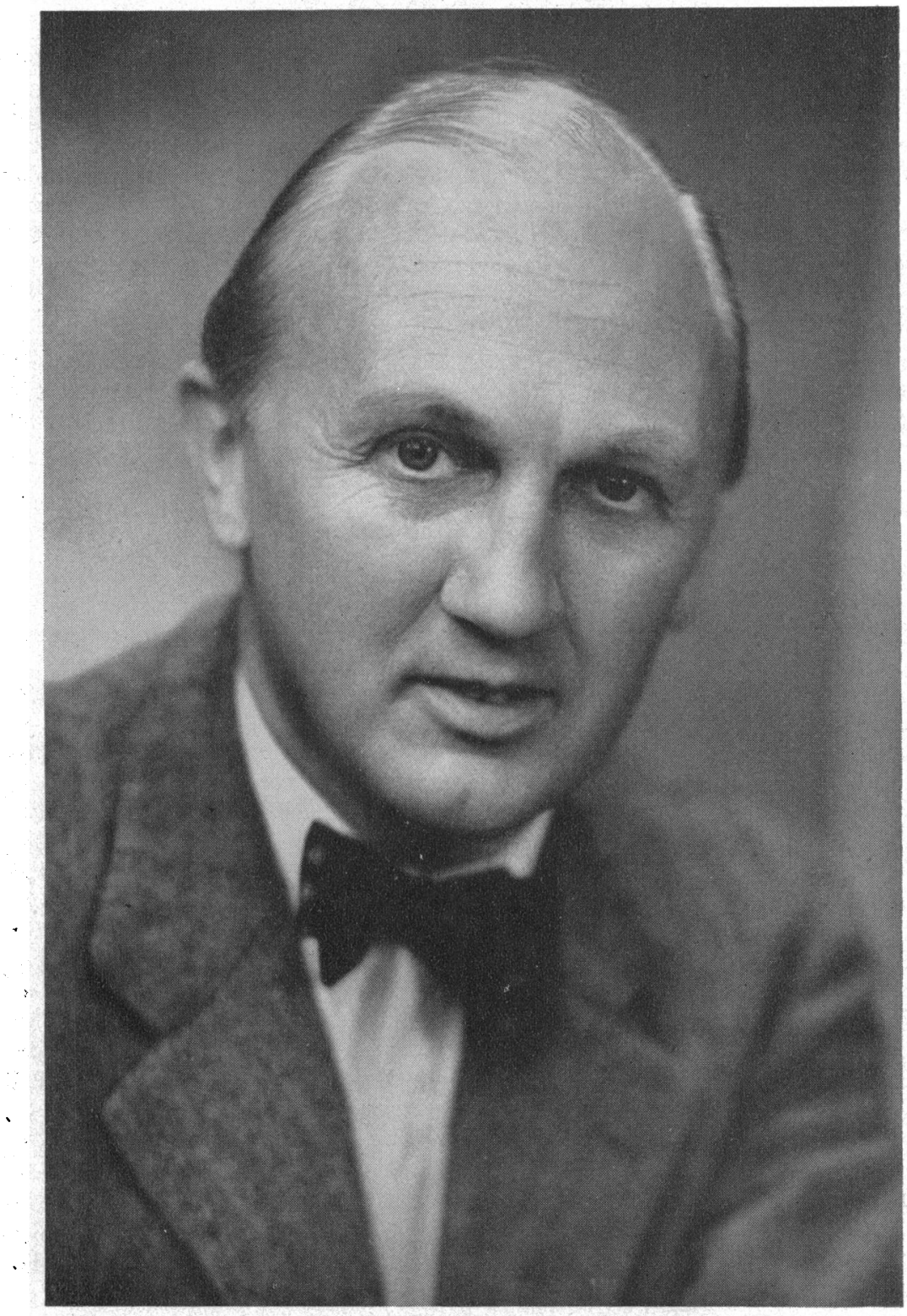

- He was a beautiful draughtsman and painted in both water colours and oils. Equable in temperament and witty, he was a delightful and interesting companion. Seymour Philps's premature death at the height of his professional career is a very great loss to ophthalmology.

Sympathy for his wife and family will be widespread.

R.S. 